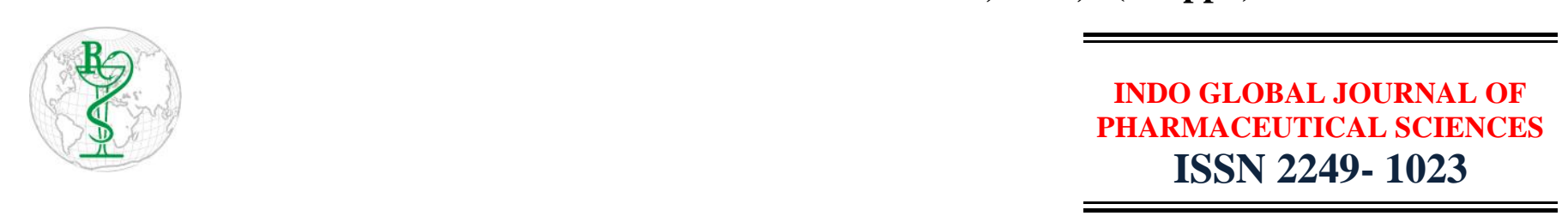

\title{
Recent Advancements in the Treatment of Anxiety by Natural Drugs
}

\author{
Nikhil Sharma ${ }^{* 1}$, Pooja Sharma ${ }^{1,2}$, Dinesh Kumar ${ }^{1}$ \\ ${ }^{1}$ Sri Sai College of Pharmacy, Manawala, Amritsar-143115, Punjab, India \\ ${ }^{2}$ Department of Pharmaceutical Sciences and Drug Research, Punjabi University Patiala, Punjab, India
}

Address for Correspondence: Nikhil Sharma; nikhil02101997@ yahoo.com

\begin{tabular}{l} 
Received: \\
01.03 .2019 \\
Accepted: \\
25.03.2019 \\
\\
Keywords \\
Anxiety; \\
Psychopharmacol \\
ogy; Anti-anxiety \\
drugs; Valeriana \\
officinalis. \\
\hline
\end{tabular}

Received:

01.03.2019

Accepted:

Keywords

Anxiety;

Psychopharmacol

drugs; Valeriana

officinalis.
ABSTRACT: Anxiety affects about total of one-eighth individuals worldwide and has become an essential field of research in psychopharmacology. It is estimated that more than 10 million populations are suffering from anxiety every year in India. Anxiety, which is a state of extreme fear and is characterized by the sympathetic hyperactivity, vigilance syndromes, motor tension and apprehension. Several anti-anxiety drugs have been used for the treatment of anxiety. Benzodiazepens are the most important category of compounds that have been used for treating anxiety, but the long term utilization of these drugs may produce physiological and psychological dependence. Furthermore, the drugs used for anxiety can cause serious adverse effects such as sleep disturbances, cholinergic symptoms, blurred vision, weight gain, gastrointestinal problems, sexual dysfunction and medication dependence. Hence, herbal medicinal plants are used for the treatment of anxiety because of their potent therapeutic activities and lesser side effects as compare to the usual anti-anxiety drugs. Some traditional plants that are used as anxiolytics are Valeriana officinalis, Tilia europeae, Chenopodium ambrosioides and Passiflora coerulea. Valerenic acid that is obtained from Valeriana officinalis, acts with the GABA-nergic system to treat anxiety. Further, more natural drugs should be invented and researched for obtaining wide range of applications. (C) 2019 iGlobal Research and Publishing Foundation. All rights reserved.

Cite this article as: Sharma, N.; Sharma, P.; Kumar, D. Recent Advancements in the Treatment of Anxiety by Natural Drugs. Indo Global J. Pharm. Sci., 2019; 9(2Suppl.): $131 . \quad$ DOI: http://doi.org/10.35652/IGJPS.2019.92S29.

Indo Global Journal of Pharmaceutical Sciences( ISSN 2249 1023; CODEN- IGJPAI; NLM ID: 101610675) indexed and abstracted in CrossRef (DOI Enabling), UGC CARE Journal List, EMBASE(Elsevier), National Library of Medicine (NLM) Catalog, ResearchGate, Publons, CAS (ACS), Index Copernicus, Google Scholar and many more. For further details, visit http://iglobaljournal.com

This is a special issue as an outcome of 'RAPSCON-2019' sponsored by APTI and organized by Sri Sai College of Pharmacy, Manawala, Amritsar, Punjab, India. Relaxation offered in journal format. 